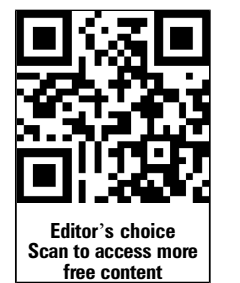

free content
${ }^{1}$ Behavioural Epidemiology Laboratory, Baker IDI Heart and Diabetes Institute, Melbourne, Victoria, Australia

${ }^{2}$ School of Exercise and Nutrition Sciences, Deakin University, Melbourne, Victoria, Australia

${ }^{3}$ School of Public Health and Social Work, Queensland University of Technology, Brisbane, Queensland, Australia

${ }^{4} \mathrm{McC}$ aughey VicHealth Centre for Community Wellbeing,

Melbourne School of Population and Global Health, University of Melbourne, Melbourne, Australia

\section{Correspondence to} Neville Owen, Behavioural Epidemiology Laboratory, Baker IDI Heart and Diabetes Institute, Melbourne, VIC 3004, Australia; neville.owen@bakeridi.edu.au

Accepted 6 December 2013

To cite: Owen N, Salmon J,
Koohsari MJ, et al. Br J
Sports Med 2014;48:
174-177.

\title{
Sedentary behaviour and health: mapping environmental and social contexts to underpin chronic disease prevention
}

\author{
Neville Owen, ${ }_{1}^{1}$ Jo Salmon, ${ }^{2}$ Mohammad Javad Koohsari, ${ }^{1}$ Gavin Turrell, ${ }^{3}$ \\ Billie Giles-Corti ${ }^{4}$
}

\section{ABSTRACT}

The time that children and adults spend sedentary-put simply, doing too much sitting as distinct from doing too little physical activity - has recently been proposed as a population-wide, ubiquitous influence on health outcomes. It has been argued that sedentary time is likely to be additional to the risks associated with insufficient moderate-to-vigorous physical activity. New evidence identifies relationships of too much sitting with overweight and obesity, type 2 diabetes, cardiovascular disease, some cancers and other adverse health outcomes. There is a need for a broader base of evidence on the likely health benefits of changing the relevant sedentary behaviours, particularly gathering evidence on underlying mechanisms and dose-response relationships. However, as remains the case for physical activity, there is a research agenda to be pursued in order to identify the potentially modifiable environmental and social determinants of sedentary behaviour. Such evidence is required so as to understand what might need to be changed in order to influence sedentary behaviours and to work towards population-wide impacts on prolonged sitting time. In this context, the research agenda needs to focus particularly on what can inform broad, evidence-based environmental and policy initiatives. We consider what has been learned from research on relationships of environmental and social attributes and physical activity; provide an overview of recent-emerging evidence on relationships of environmental attributes with sedentary behaviour; argue for the importance of conducting international comparative studies and addressing life-stage issues and socioeconomic inequalities and we propose a conceptual model within which this research agenda may be addressed.

\section{INTRODUCTION}

In the context of the major 'diseases of inactivity', sedentary behaviour-too much sitting-has emerged as a significant additional element of the chronic disease prevention agenda. The Sedentary Behaviour Research Network ${ }^{2}$ proposes the following definition: 'any waking behaviour characterised by an energy expenditure $\leq 1.5$ metabolic equivalents (METs; put simply, multiples of the basal metabolic rate) while in a sitting or reclining posture' (p.540). A rapidly developing body of recent evidence has identified prolonged sitting time as a population-wide, ubiquitous health risk. ${ }^{3}$ In adults, too much sitting is related to risk for type 2 diabetes, cardiovascular disease, breast and colon cancer and poor mental health outcomes. ${ }^{3-5}$ In children, sedentary time is related to overweight and obesity, some cardiovascular risk factors (eg, elevated systolic blood pressure) and poorer cognitive development (eg, language delay). ${ }^{6}$ Less is known about cardiometabolic health consequences for older adults, but preliminary findings suggest a likely importance.

As illustrated in figure 1, sedentary time is ubiquitous. It accumulates each day while commuting, at school, in the workplace, at home and in leisure contexts. There are deleterious metabolic consequences of the 6-10 $\mathrm{b}$ of sitting to which children and adults can be exposed to each day. ${ }^{8} 9$ Sitting time, together with reduced requirements for physical activity, ${ }^{10}{ }^{11}$ has increased significantly over the past several decades, due to a range of economic, social, environmental and technological changes, including the increased use of screen-based entertainment and communication devices, more outer suburban development and increased motorised transport. ${ }^{12}$

There is now a need to address the nexus of new research perspectives on the adverse health outcomes of sitting time, within a broader understanding of environmental influences on health behaviours, ${ }^{3}$ taking an ecological ${ }^{13} 14$ and socioeconomic inequalities ${ }^{15}$ perspective across life stages.

We provide a basis for taking this agenda forward, through considering what has been learned from research on environmental attributes and physical activity relationships; and provide an overview of the recent evidence on relationships of environmental attributes with sedentary behaviour; argue for the importance of international comparative studies and addressing life-stage and socioeconomic inequalities and propose a conceptual model (illustrated in figure 2) within which this research agenda may be addressed.

\section{Recent lessons from research on environment- physical activity relationships}

There has been consistent evidence over the past decade for the built environment as a significant correlate of physical activity. Different environment attributes have been found to be associated with physical activity for recreation and transportation-related activity. ${ }^{16-18}$ For example, for transport-related walking, built environmental attributes have been conceptualised around the notion of 'walkability', which takes into account street connectivity, residential density and land-use. For recreational walking, among other things, neighbourhood aesthetics are more important. There are lessons from this body of research that can guide the future research on the role of the built environment on sedentary behaviour 


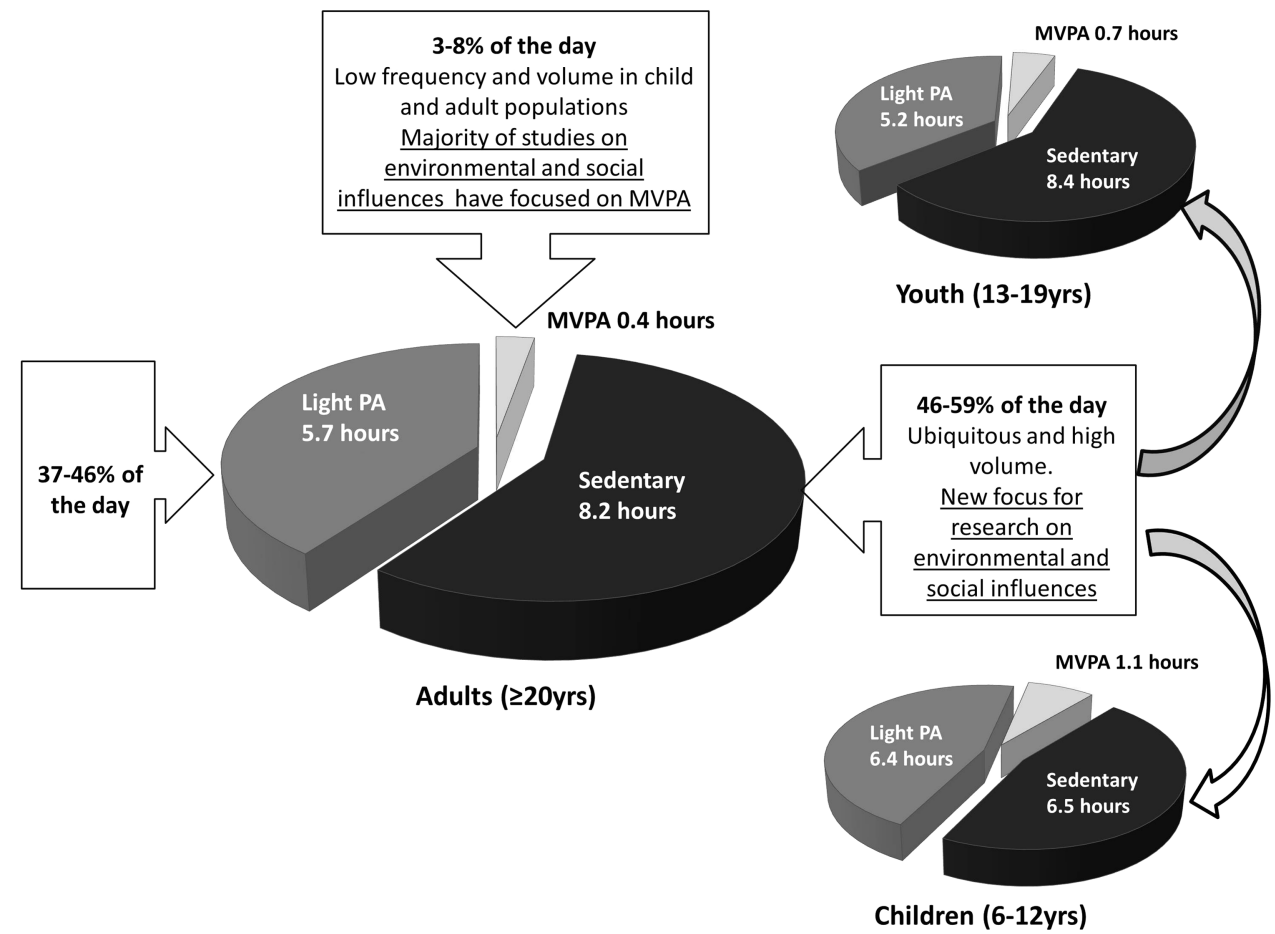

Figure 1 How adults and children typically allocate their time spent sedentary, in light-intensity physical activity and moderate-to-vigorous intensity physical activity (based on population data from the 2003-2006 NHANES survey). ${ }^{58}$

particularly related to use of behaviour and context-specific measures. $19-21$

However, variability in physical activity for different population subgroups also raises several questions for future sedentary behaviour studies. For example, high-walkable neighbourhoods
- that have higher residential density and more destinationsoften have more traffic, and exposure to traffic is negatively associated with active forms of transport in children. ${ }^{22-24}$ In the context of physical activity research, there is a paucity of age differences in response to environmental exposures. ${ }^{25} 26$ Frank

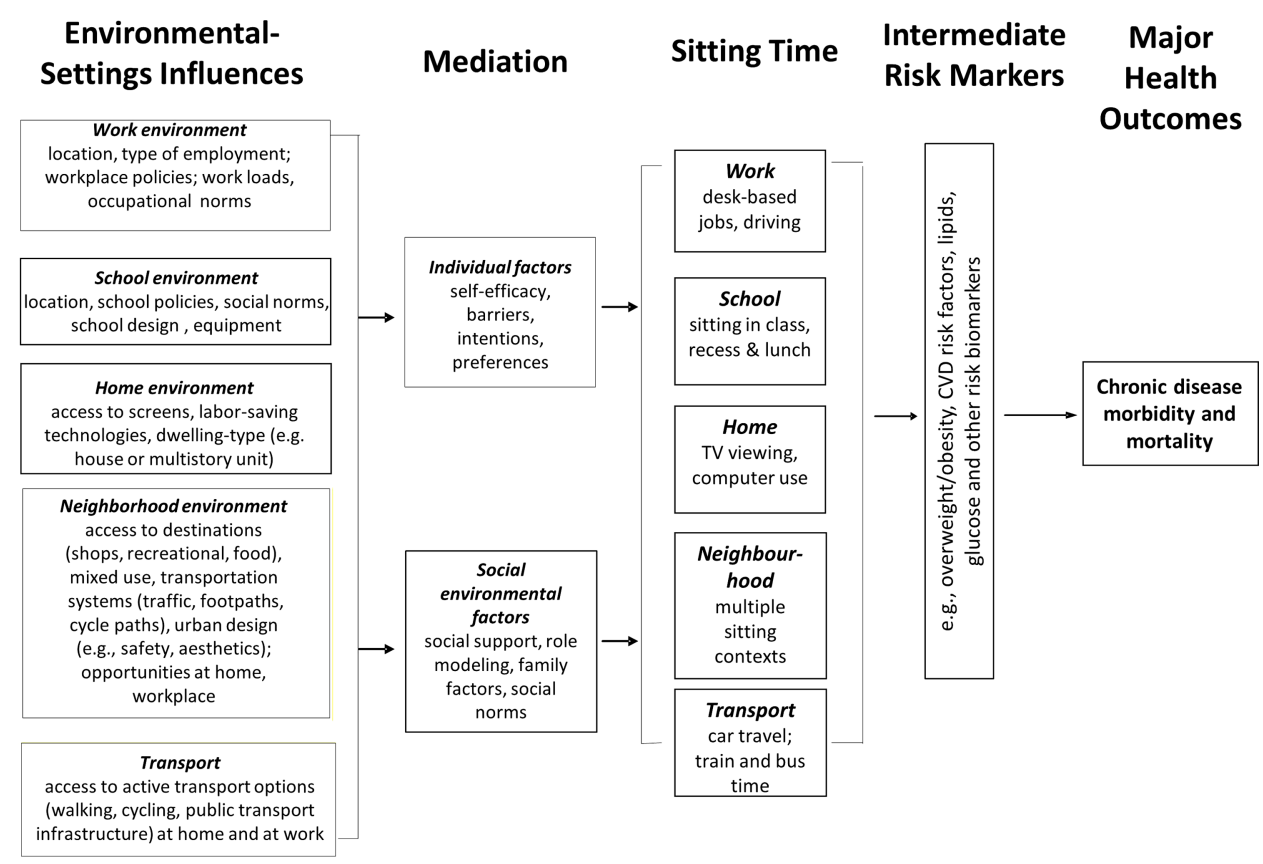

Moderation (demographic and biological factors age, gender, race/ethnicity, socioeconomic status, adiposity, genetics)

Figure 2 Overview of relationships that need to be identified — between the built, policy and social environments, prolonged sitting in particular settings and chronic disease risk (modified from Villanueva et $a^{26}$ ). 
et $a^{27}$ examined urban form relationships with walking among youth aged 5-20 years, stratifying the sample by age group. They found significant differences in walking frequency and distance by age group, and differential relationships between the built form and behaviour by age. In a recent study in Belgium, Van Dyck et $a l^{28}$ examined the influence of perceived environmental attributes on active transportation among adults and adolescents. They found perceived residential density, land-use mix, safety for cycling and walkability to be associated with active transportation in adults but not adolescents. Inconsistencies in previous physical activity research findings may at least in part be explained by differential responses to the environment by different population segments. For example, proximity from home to parks and recreational facilities is commonly associated with higher levels of physical activity ${ }^{29}$ but the role of particular attributes appear to differ by population subgroups. For example, while the use of public open space almost halves as distance doubles, various studies involving adults have found that the quality and size of public open space rather than its proximity was positively associated with higher levels of walking in adults. ${ }^{30} 31$ Similarly, facilities within parks have also been found to be more important than proximity for children's physical activity. ${ }^{32}$

Consistencies and variations in such relationships by life-stage for sedentary behaviours are highly likely. For example, older adults and children tend to spend larger parts of their daily lives in their neighbourhoods than do working-age adults. On the other hand, working adults are more mobile and have easier access to facilities and services in surrounding areas or near work locations; older adults and children may rely more on local opportunities for spending time outdoors.

\section{The built environment and sedentary behaviour}

To date, only a small number of studies have focused on how the built environment is associated with sedentary behaviour and have primarily examined TV viewing time. In Australia, Sugiyama et $a l^{33}$ found that low levels of objectively assessed neighbourhood walkability (poorly connected streets, low levels of residential density, limited land-use diversity and large parking spaces for retail access) were positively associated with TV viewing time. For older women in Japanese cities, Kikuchi et $a l^{34}$ found TV viewing time to be associated with contextual factors such as location of residence, living with others and nondriving status. Women living in low-walkable communities reported significantly more minutes of daily TV viewing time, after controlling for the influences of area level socioeconomic status and relevant sociodemographic attributes. ${ }^{34}$

Evidence from prospective studies with adults and children suggests that the built environment is an important determinant of TV viewing time and other screen behaviours. In a recent 4-year follow-up study, Ding et $a l^{35}$ identified that adults in lowwalkable neighbourhoods increased their TV viewing time compared with those who lived in high-walkable neighbourhoods. In another longitudinal study of associations between the neighbourhood environment and child and youth screen time, Timperio et $a l^{25}$ and Veitch et $a l^{32}$ found that relationships varied depending on the neighbourhood features being examined and on the screen behaviour of interest (eg, TV viewing time, computer use or electronic games use).

A recent review of child and youth sedentary behaviour reported that neighbourhood environmental factors such as topography, living in urban areas and perceived neighbourhood safety to be key correlates. ${ }^{6}$ Living in suburban versus traditional neighbourhoods, limited public transport availability and lower population density have been found to be associated with greater time spent sitting in cars. ${ }^{16}$ A study of $10-12$-year-old children living in inner West Sydney found that $40 \%$ were driven to and from school every day, and of those children just under $50 \%$ lived within $1.5 \mathrm{~km}$ of school. ${ }^{36}$ Among primary and secondary school children and their parents living in Melbourne, Carver et $a l^{37}$ found that parental concerns regarding traffic injury were positively associated and social trust was inversely associated with parental chauffeuring of their children. Research with primary and secondary school children has found similar variables associated with parental chauffeuring of their children (eg, household car access, distance to school) as well as social trust, concerns about injury while crossing a road, age and sex of the child, one parent not in full-time work and urban/rural location. ${ }^{6}$ Aspects of neighbourhood design around schools and distance from home to school have been shown to significantly impact whether children walk, cycle or whether they are driven to school, highlighting the importance of betterinformed urban-transport policy for influencing sitting time en-route to and from school. ${ }^{23} 38$

This emerging body of evidence on sedentary behaviour/ environment relationships includes more extensive evidence for children than it does for adults or older adults. There is a particular need for evidence from observational studies-particularly prospective studies-examining environmental and social determinants of sedentary behaviour for adults at different life stages.

\section{Maximising variations in environmental exposures through international studies}

Bauman et $a l^{39}$ reported striking differences in prevalence and gender variations in adults' overall sitting time within 21 countries that they examined. While the authors are cautious not to speculate, their findings suggest the merit of examining findings from countries that have differing built environment, transportation infrastructure and cultural and social attributes, and that vary in their stage of economic development. These initial findings make clear that a central problem for understanding how environmental and social factors can influence sedentary behaviours is that there may be too little variation in social, environmental and policy variables across units of study in single countries.

In contrast to the Australian findings described above ${ }^{33}$ and findings from the USA, ${ }^{40}$ for the Belgian sample, those living in high-walkable neighbourhoods reported significantly more sitting time than those from low-walkable neighbourhoods (472 vs $418 \mathrm{~min}$ on weekdays, respectively; 440 vs $403 \mathrm{~min}$ on weekend days, respectively). Notably, the Belgian findings are on self-reported overall sitting time and accelerometer-measured total sedentary time, which may explain the differences in findings. ${ }^{41}{ }^{42}$ However, it may also suggest that built environmental attributes influence sedentary behaviour differently in older European cities; point to potential social and cultural differences that warrant further examination; and highlight the complexities of urban planning policy advice to avoid 'unintended consequences'.

Given that much of the evidence on the relationship of environmental attributes with sedentary behaviour comes from studies in Australia, Belgium and the USA, the full range of these environmental exposures and their impacts remain to be examined. There is considerable potential for greater explanatory power in identifying the relevant environment/behaviour relationships. 


\section{Addressing life-stage and socioeconomic factors within and across studies}

Where life-stage and socially related comparisons are made within studies, the usual focus is on how various built environmental features may affect a specific population segment, rather than how the impact of these features may differ across social groups. Studies thus tend to focus on a particular population segment (most usually the general adult population), or the analysis methods used will filter out variability by adjusting the findings for age, sex and other personal characteristics (eg, socioeconomic status) that are likely to cause differences in outcome variables.

There have been a number of studies on the social correlates of TV viewing time ${ }^{6} 43^{44}$ and the role of socioeconomic inequalities has to some extent been explored. For example, Hesketh et $a l^{45}$ found that maternal education and children's TV viewing were partly mediated by aspects of the family television environment. Salmon et $a l^{46}$ reported that enjoyment of television and perceived barriers to physical activity (cost, work commitments) were predictors of high TV viewing time $(>14 \mathrm{~h} /$ week) among a large sample of Australian adults. Clark et $a l^{41}$ showed that Australian adults with lower levels of educational attainment and living in rural areas were more likely to be in the highest TV viewing time categories. Using the American Cancer Society data from a large population-based study, King et $a l^{47}$ identified clusters of adults in the $4 \mathrm{~h}$ or more per day category of TV time who had low levels of educational attainment.

The future research should address the knowledge-gap on associations of socioeconomic inequalities with sedentary behaviours and their adverse health outcomes from a multilevel, longitudinal and life-course perspective. ${ }^{48} 49$ There is a need for area-level social inequalities to be better understood-for example, those living in areas with low perceived social capital or those who are fearful of local crime may constrain their physical and social activities and be more likely to stay indoors and watch TV. ${ }^{50}$ Broadly, there is a need to examine how associations between socioeconomic inequalities and sedentary behaviour are influenced by the contributions of neighbourhood-level, household-level and individual-level factors, how these multilevel factors and sitting time change over time and how these factors shape and circumscribe inequalities at different time points across the life course. ${ }^{51}$

These new directions will yield important findings relevant to the role of environmental attributes at different life stages. For example, there are likely to be important differences in environmental factors and their relationships with socioeconomic inequalities, which may either similarly or differentially influence children, adults or older adults. ${ }^{52}$ There is a compelling need for such relationships to be fully explored ${ }^{53} 54$ and for new conceptual approaches, measurements and methodological strategies to address explicitly the role of socioeconomic inequalities. ${ }^{55-57}$

\section{Conclusions: comprehensive, policy-relevant evidence on sitting time and chronic disease prevention}

Figure 2 depicts a conceptual framework that can guide future studies to identify the determinants of sedentary behaviour in multiple settings. Evidence is needed to map the links between each of the elements within this framework. There is a need to examine the potential mediating roles of sitting time in particular contexts (school, workplace, transportation and domestic environments) between the attributes of those environments, biomarkers of health risk and health outcomes. Furthermore, evidence is needed on the potentially moderating roles of socioeconomic inequality in these contexts.

Figure 2 illustrates the comprehensive body of evidence that is now needed to inform future environmental and policy initiatives needed to reduce sitting time, thereby expanding the options for chronic disease prevention-not only through public health, but also through urban planning, transport and other sectors. The conceptual model in figure 2 highlights the need for quantitative rigour within this research agenda. In particular, there is the need to apply the relevant analytical methods for understanding the likely moderating roles of social factors on sedentary behaviour, as well as the factors that may operate to mediate the relationships of environmental attributes with prolonged sitting in particular contexts-the 'behaviour settings' provided by school, occupational, commuting and domesticentertainment contexts in which children and adults spend large proportions of their waking hours. ${ }^{13} 14$

The future research also needs to examine the differences in these relationships as a function of key life stages-childhood and adolescence, adulthood and older adult life-identifying the common and distinct influences of environmental, social and other relevant determinants of sitting time in relevant settings.

Pursuing a comprehensive and well-coordinated research agenda on environmental attributes, sedentary behaviour and health outcomes has great potential to inform research translation in the context of chronic disease prevention. There is an urgent need to develop interdisciplinary research methodologies and identify where specific opportunities for evidence-informed environmental and policy initiatives may be pursued. For policy makers and practitioners in public health, urban design and planning, transport and other sectors, these findings will identify additional opportunities for interdisciplinary and intersectoral collaboration that are directed at reducing sedentary time, leading to broad-reaching health and social benefits.

Contributors NO, JS, GT and BG-C contributed equally to the literature review, conceptualising, planning and writing the article. MJK contributed to the conceptual refinement, literature review, manuscript structuring and referencing. NO takes overall responsibility for the content of the article.

Competing interests NO is supported by a National Health and Medical Research Council of Australia (NHMRC) Programme Grant (\#569940), a Senior Principal Research Fellowship (NHMRC \#1003960) and the Victorian Government's Operational Infrastructure Support Programme. JS is supported by an NHMRC Principal Research Fellowship (\#APP1026216). MJK is supported by an NHMRC Programme Grant (\#569940) and by the Victorian Government's Operational Infrastructure Support Programme. GT is supported by an NHMRC Senior Research Fellowship (\#1003710) and BG-C by an NHMRC Principal Research Fellowship (\#1004900)

Provenance and peer review Not commissioned; externally peer reviewed.

\section{REFERENCES}

1 Lee IM, Shiroma EJ, Lobelo F, et al. Effect of physical inactivity on major non-communicable diseases worldwide: an analysis of burden of disease and life expectancy. Lancet 2012;380:219-29.

2 Sedentary Behaviour Research Network. Letter to the editor: standardized use of the terms 'sedentary' and 'sedentary behaviours'. Appl Physiol Nutr Metab 2012;37:540-2

3 Veerman JL, Healy GN, Cobiac LJ, et al. Television viewing time and reduced life expectancy: a life table analysis. Br J Sports Med 2012;46:927-30.

4 Owen $N$, Healy GN, Matthews $C E$, et al. Too much sitting: the population health science of sedentary behavior. Exerc Sport Sci Rev 2010;38:105-13.

5 Tremblay MS, Colley RC, Saunders TJ, et al. Physiological and health implications of a sedentary lifestyle. App/ Physiol Nutr Metab 2010;35:725-40.

6 Salmon J, Tremblay MS, Marshall SJ, et al. Health risks, correlates, and interventions to reduce sedentary behavior in young people. Am J Prev Med 2011;41:197-206.

7 Gardiner PA, Healy GN, Eakin EG, et al. Associations between television viewing time and overall sitting time with the metabolic syndrome in older men and 
women: the Australian diabetes obesity and lifestyle study. J Am Geriatr Soc 2011;59:788-96.

8 Healy GN, Clark BK, Winkler EAH, et al. Measurement of adults' sedentary time in population-based studies. Am J Prev Med 2011;41:216-27.

9 Owen N, Sparling PB, Healy GN, et al. Sedentary behavior: emerging evidence for a new health risk. Mayo Clin Proc 2010;85:1138-41.

10 Ng SW, Popkin BM. Time use and physical activity: a shift away from movement across the globe. Obes Rev 2012;13:659-80.

11 Lakerveld J, Dunstan D, Bot S, et al. Abdominal obesity, TV-viewing time and prospective declines in physical activity. Prev Med 2011;53:299-302.

12 Sugiyama T, Merom D, van der Ploeg HP, et al. Prolonged sitting in cars: prevalence, socio-demographic variations, and trends. Prev Med 2012;55:315-18.

13 Sallis JF, Owen N, Fisher EB. Ecological models of health behavior. In: Glanz BK, Rimer K, Viswanath K. eds Health behavior and health education: theory, research and practice San Francisco. San Francisco: Jossey-Bass, 2008:465-82.

14 Owen N, Sugiyama T, Eakin EE, et al. Adults' sedentary behavior: determinants and interventions. Am J Prev Med 2011;41:189-96.

15 Turrell G, Oldenburg B, McGuffog I, et al. Socioeconomic determinants of health: towards a national research program and a policy and intervention agenda. Queensland University of Technology, School of Public Health, Ausinfo: Canberra, 199930 August 2013. Report No.

16 Sugiyama T, Neuhaus $M$, Cole $R$, et al. Destination and route attributes associated with adults' walking: a review. Med Sci Sports Exerc 2012;44:1275-86.

17 Sallis JF, Floyd MF, Rodríguez DA, et al. Role of built environments in physical activity, obesity, and cardiovascular disease. Circulation 2012;125:729-37.

18 Saelens BE, Handy SL. Built environment correlates of walking: a review. Med Sci Sports Exerc 2008;40:S550-66.

19 Giles-Corti B, Timperio A, Bull F, et al. Understanding physical activity environmental correlates: increased specificity for ecological models. Exerc Sport SCi Rev 2005;33:175-81.

20 Humpel N, Owen N, Leslie E. Environmental factors associated with adults' participation in physical activity: a review. Am J Prev Med 2002;22:188-99.

21 Owen $N$, Humpel $N$, Leslie $E$, et al. Understanding environmental influences on walking: review and research agenda. Am J Prev Med 2004;27:67-76.

22 King WC, Brach JS, Belle $S$, et al. The relationship between convenience of destinations and walking levels in older women. Am J Health Promot 2003;18:74-82.

23 Giles-Corti B, Wood G, Pikora T, et al. School site and the potential to walk to school: the impact of street connectivity and traffic exposure in school neighborhoods. Health Place 2011;17:545-50

24 Villanueva K, Giles-Corti B, Bulsara M, et al. Where do children travel to and what local opportunities are available? the relationship between neighborhood destinations and children's independent mobility. Environ Behav 2013:45:679-705.

25 Timperio A, Ball K, Salmon J, et al. Personal, family, social, and environmental correlates of active commuting to school. Am J Prev Med 2006:30:45-51.

26 Villanueva K, Pereira G, Knuiman $M$, et al. The impact of the built environment on health across the life course: design of a cross-sectional data linkage study. BMJ Open 2013;3:pii:e002482.

27 Frank L, Kerr J, Chapman J, et al. Urban form relationships with walk trip frequency and distance among youth. Am J Health Promot 2007;21:305-11.

28 Van Dyck D, De Meester F, Cardon G, et al. Physical environmental attributes and active transportation in Belgium: what about adults and adolescents living in the same neighborhoods? Am J Health Promot 2013;27:330-8.

29 Kaczynski AT, Henderson KA. Environmental correlates of physical activity: a review of evidence about parks and recreation. Leisure Sci 2007;29:315-54.

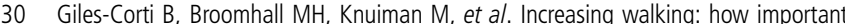
is distance to, attractiveness, and size of public open space? Am J Prev Med 2005;28:169-76.

31 Sugiyama T, Francis J, Middleton NJ, et al. Associations between recreational walking and attractiveness, size, and proximity of neighborhood open spaces. Am J Public Health 2010;100:1752-7.

32 Veitch J, Timperio A, Crawford D, et al. Is the neighbourhood environment associated with sedentary behaviour outside of school hours among children? Ann Behav Med 2011;41:333-41.

33 Sugiyama T, Salmon J, Dunstan DW, et al. Neighborhood walkability and TV viewing time among Australian adults. Am J Prev Med 2007;33:444-9.

34 Kikuchi $\mathrm{H}$, Inoue $\mathrm{S}$, Sugiyama $\mathrm{T}$, et al. Correlates of prolonged television viewing time in older Japanese men and women. BMC Public Health 2013;13:213.
35 Ding $D$, Sugiyama $T$, Winkler $E$, et al. Correlates of change in adults' television viewing time: a four-year follow-up study. Med Sci Sports Exerc 2012;44:1287-92.

36 Wen LM, Fry D, Rissel C, et al. Factors associated with children being driven to school: implications for walk to school programs. Health Educ Res 2008:23:325-34

37 Carver A, Timperio A, Crawford D. Parental chauffeurs: what drives their transport choice? J Transp Geogr 2013;26:72-7.

38 Trapp G, Giles-Corti B, Christian H, et al. On your bike! A cross-sectional study of the individual, social and environmental correlates of cycling to school. Int J Behav Nutr Phys Act 2011;8:123.

39 Bauman A, Ainsworth BE, Sallis JF, et al. The descriptive epidemiology of sitting: a 20-country comparison using the International Physical Activity Questionnaire (IPAQ). Am J Prev Med 2011;41:228-35.

40 Kozo J, Sallis J, Conway T, et al. Sedentary behaviors of adults in relation to neighborhood walkability and income. Health Psychol 2012;31:704-13.

41 Clark BK, Sugiyama T, Healy GN, et al. Socio-demographic correlates of prolonged television viewing time in Australian men and women: The AusDiab Study. J Phys Act Health 2010;7:595-601.

42 Van Dyck D, Cerin E, Conway T, et al. Associations between perceived neighborhood environmental attributes and adults' sedentary behavior: findings from the USA, Australia and Belgium. Soc Sci Med 2012;74:1375-84.

43 Van Der Horst K, Chinapaw MJ, Twisk JW, et al. A brief review on correlates of physical activity and sedentariness in youth. Med Sci Sports Exerc 2007;39:1241-50.

44 Salmon J, Timperio A, Telford A, et al. Association of family environment with children's television viewing and with low level of physical activity. Obes Res 2005;13:1939-51.

45 Hesketh K, Ball K, Crawford D, et al. Mediators of the relationship between maternal education and children's TV viewing. Am J Prev Med 2007;33:41-7.

46 Salmon J, Owen N, Crawford D, et al. Physical activity and sedentary behavior: a population-based study of barriers, enjoyment, and preference. Health Psychol 2003;22:178-88

47 King AC, Goldberg JH, Salmon J, et al. Identifying subgroups of US adults at risk for prolonged television viewing to inform program development. Am J Prev Med 2010;38:17-26

48 Burton N, Haynes M, Wilson L-A, et al. HABITAT: a longitudinal multilevel study of physical activity change in mid-aged adults. BMC Public Health 2009;9:76.

49 Kamphuis CB, Turrell G, Giskes K, et al. Life course socioeconomic conditions, adulthood risk factors and cardiovascular mortality among men and women: a 17-year follow up of the GLOBE study. Int J Cardiol 2013;168:2207-13.

50 Foster S, Giles-Corti B, Knuiman M. Neighbourhood design and fear of crime: a social-ecological examination of the correlates of residents' fear in new suburban housing developments. Health Place 2010;16:1156-65.

51 Turrell G, Lynch JW, Leite C, et al. Socioeconomic disadvantage in childhood and across the life course and all-cause mortality and physical function in adulthood: evidence from the Alameda County Study. J Epidemiol Community Health 2007:61:723-30.

52 Badland H, Turrell G, Giles-Corti B. Who does well where? Exploring how self-rated health differs across diverse people and neighborhoods. Health Place 2013:22:82-9.

53 Burton NW, Haynes M, van Uffelen JGZ, et al. Mid-aged adults' sitting time in three contexts. Am J Prev Med 2012:42:363-73.

54 Cerin E. Statistical approaches to testing the relationships of the built environment with resident-level physical activity behavior and health outcomes in cross-sectional studies with cluster sampling. J Plann Lit 2010;26:151-67.

55 Turrell G, Haynes M, Burton NW, et al. Neighborhood disadvantage and physical activity: baseline results from the HABITAT multilevel longitudinal study. Ann Epidemiol 2010;20:171-81.

56 Turrell G, Haynes M, Wilson L-A, et al. Can the built environment reduce health inequalities? A study of neighbourhood socioeconomic disadvantage and walking for transport. Health Place 2013:19:89-98.

57 Turrell G, Haynes M, O'Flaherty M, et al. Test-retest reliability of perceptions of the neighborhood environment for physical activity by socioeconomic status. J Phys Act Health 2011;8:829-40.

58 Centers for Disease Control and Prevention (CDC), National Center for Health Statistics (NCHS). National health and nutrition examination survey data 2003 2004, 2005-2006. 2009 [30 Aug 2013]. http://www.cdc.gov/nchs/nhanes/ nhanes2003-2004/nhanes03_04.htm 